\title{
A Retrospective Study: When Should We Give Antibiotics to Patients with Febrile Neutropenia in the Emergency Department?
}

\author{
(1) Mustafa Korkut ${ }^{1}$, (1) Seçgin Söyüncü ${ }^{2}$, (1) Ali AvcI ${ }^{3}$, (1) Fırat Bektaș² \\ 1Department of Emergency Medicine, University of Health Sciences Training and Research Hospital, Antalya, Turkey \\ 2Department of Emergency Medicine, Akdeniz University Faculty of Medicine, Antalya, Turkey \\ ${ }^{3}$ Clinic of Emergency Medicine, Karaman State Hospital, Karaman, Turkey
}

\begin{abstract}
Aim: Febrile neutropenia (FN) is considered to be one of the most important and potentially life-threatening oncologic diseases in the emergency department. Our study aimed to determine whether there is an effective time for decreasing the mortality at the end of the first month after antibiotic administration.

Materials and Methods: This study was designed as a retrospective cohort study. The study population consisted of FN patients who had malignancy $>18$ years and were admitted to the university hospital between January 2002 and July 2014. A total of 645 patients were included in the study. Of the patients, 322 patients were included in the analysis. The cut-off value for antibiotic administration was determined as $\leq 6$ hours vs $>6$ hours.

Results: The median age was 54 years, and 173 (53.7\%) of the patients were male. Hematological and lung malignancies were found most frequently (46.9\%, 12.4\%, respectively). The median value of antibiotic administration was 247 minutes, and the mortality rate at the end of the first month was $24.5 \%$. In the logistic regression analysis, the probability of death at the end of the first month in patients who had antibiotic administration $>6$ hours was found 2.436 times higher than the other group.

Conclusion: As a result, we found that the administration of the first dose of antibiotics to $f$ FN patients in the first 6 hours is effective in reducing mortality.
\end{abstract}

Keywords: Febrile neutropenia, mortality, time of antibiotic administration

\section{Introduction}

Infection is the most important cause of mortality and morbidity in patients with malignancy. The characteristic feature of these patients is the presence of neutropenia, which causes immunosuppression. It is known that severe febrile neutropenia (FN) patients with absolute neutrophil counts $<500-1000$ cells/ $\mathrm{mL}$ and fever over $38^{\circ} \mathrm{C}$ are associated with an increased risk of severe bacterial infection $(1,2)$.

FN is considered one of the most important and potentially lifethreatening oncologic diseases in the emergency department (ED). The deficiency of neutrophils disrupts the inflammatory response, so clinical signs and symptoms may remain confidential in these patients. Therefore, these patients should be treated early, and treatment with broad-spectrum antibiotics should be started. Studies have shown that this reduces the mortality rate (3-5). Cancer patients with FN often refer to ED. These patients may wait a long time for diagnosis and initial treatment, and such delays are associated with increased mortality $(6,7)$.

After fever is detected within one hour, various clinical guidelines recommend starting broad-spectrum antibiotics $(3,8)$. There is no specific guideline recommendation regarding antibiotic administration time (AAT) indicated to reduce mortality in FN patients. If AAT is too long, the length of hospital stay increases in 
adult patients (3,8-11). It seems reasonable to administer the first dose of antibiotics shortly after the first visit to the ED.

This study aimed to determine the relationship between AAT and outcomes in patients with cancer who presented with FN at the ED.

\section{Materials and Methods}

\section{Study Design}

This was a retrospective cohort study that evaluated clinical manifestations, risk factors, and outcomes in patients with cancer who presented with FN at the ED from January 2002 and July 2014. This study was conducted in a university hospital and was approved by the institutional review board of the hospital. A total of 645 patients were enrolled in this study. Our inclusion criteria for this study were patients with malignancies and aged $\geq 18$ years. Three hundred twenty-two patients were included in the analysis. Patients who were diagnosed with neutropenia and fever without an ED visit and who had missing data, especially for follow-up, were not included in the study (Figure 1).

\section{Treatment Protocol}

According to the International FN guidelines, antibiotics were given to the patients (12).

\section{Definitions}

Definitions were prepared according to the Infectious Diseases Society of America (3). Oral or axillary temperature equal to

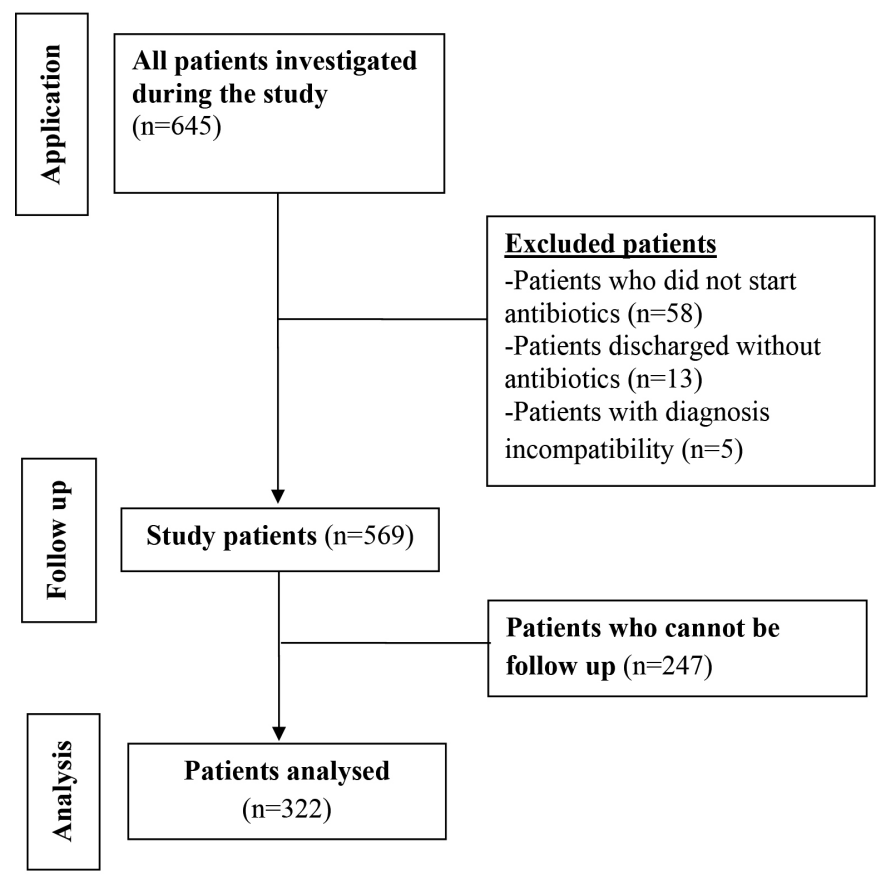

Figure 1. Patient flow chart $38.3^{\circ} \mathrm{C}$ and above for one time or $38.0-38.2^{\circ} \mathrm{C}$ for one hour was defined as fever. Neutropenia was defined as a neutrophil level less than $500 / \mathrm{mm}^{3}$, or a neutrophil level between $500-1000 / \mathrm{mm}^{3}$ and an expected fall below $500 / \mathrm{mm}^{3}$ in 48 hours. According to these, the patients were considered as FN patients.

The number of neutrophils at the time of the ED visit was categorized into two groups as severe neutropenic (neutrophil level $<100 / \mathrm{mm}^{3}$ ) and neutropenic (neutrophil level $<500 /$ $\mathrm{mm}^{3}$ ) groups. Outpatient neutrophil counts were grouped as severe neutropenic (neutrophil level $<100 / \mathrm{mm}^{3}$ ), neutropenic (neutrophil level $<500 / \mathrm{mm}^{3}$ ) and normal (neutrophil level 500$\left.1000 / \mathrm{mm}^{3}\right)$.

AAT was defined as the time from triage to the first dose of parenteral antibiotic administration. Length of stay (LOS) and survival time to hospital discharge were calculated as well. The LOS in the ED was defined as the time from triage to the hospitalization or referral to another hospital.

This study was approved by the Ethics Committee of Akdeniz University. The study was conducted following the ethical principles of Helsinki.

\section{Statistical Analysis}

Kolmogorov-Smirnov test was used to assess normality. Normally distributed data were given as mean \pm standard deviation. Nonnormally distributed data were analyzed using Mann-Whitney U test and were presented as median for the continuous variables and percentage for the categorical variables. Dependent variables were associated with deaths at the end of the first month. Independent variables were age, gender, seasonal period, LOS in the ED, vital signs, use of Granulocyte colonystimulating factor (G-CSF), pre-admission antibiotic usage, count of applied neutrophils, count of discharged neutrophil, underlying malignancy causes, comorbidities, AAT and the antibiotic protocols, the last chemotherapy and radiotherapy (RT), blood, urine cultures with results. A chi-square test was used to analyze the end of first-month mortality. Logistic regression analysis was performed using independent variables that affect the mortality relationship. Antibiotic timing at each timing cutoff and adjusted odds ratios with 95\% confidence intervals for the outcomes were presented. All hypotheses were constructed bidirectional, and the alpha critical value was defined to be 0.05 . SPSS 20.0 statistical package program was used for statistical evaluation of our research data.

\section{Results}

A total of 322 patients with diagnosed $\mathrm{FN}$ were included in the analysis. There were 173 (53.7\%) males and 149 (46.3\%) females 
with a male to female ratio of 1.16:1. The median age was 54 years. Hematological and lung malignancies were the most common malignancies $(46.9 \%, 12.4 \%$, respectively). The basic characteristics of the patients are described in Table 1.

The median LOS in the ED was 3 hours. The duration of admission to ED was ten days for chemotherapy and 39 days for RT. G-CSF was given to 149 (46.3\%) patients. Thirty-seven patients (11.4\%) have pre-admission antibiotic usage. The causes of infection are shown in Figure 2.

The median value of AAT was 247 minutes, and the mortality rate at the end of the first month was $24.5 \%$. The primary

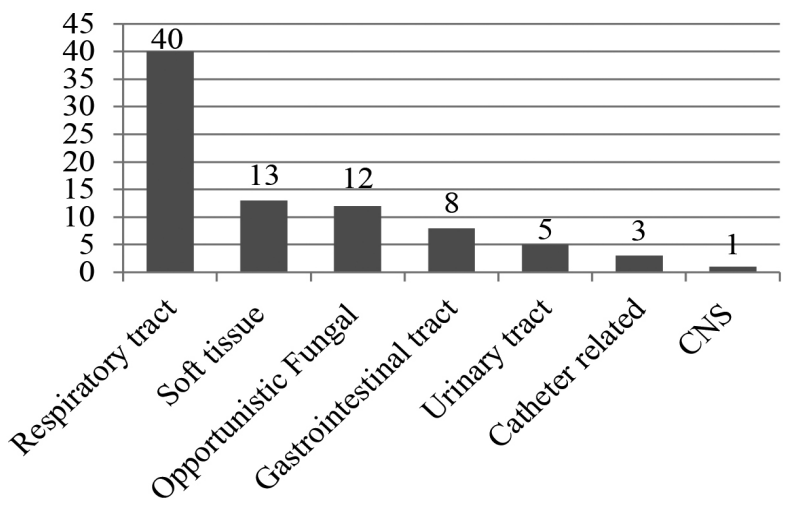

Figure 2. Sources of infection (n)

CNS: Central nervous system

Table 1. Demographic variables of patients

\begin{tabular}{ll}
\hline Variable & \\
\hline Gender & $173(53.7)$ \\
\hline Male, $\mathbf{n}(\%)$ & 54 \\
\hline Age, median & $151(46.9)$ \\
\hline Diagnosis, $\mathbf{n}(\%)$ & $40(12.4)$ \\
Hematological malignancies & $27(8.4)$ \\
Lung cancer & $25(7.8)$ \\
Gastrointestinal tumors & $23(7.1)$ \\
Breast cancer & $18(5.6)$ \\
Musculoskeletal system tumors & $17(5.3)$ \\
Urogenital tumors & $12(3.7)$ \\
Head and neck tumors & $9(2.8)$ \\
Unknown primary tumors & \\
Central Nervous system tumors & $70(62.5)$ \\
\hline Comorbidities, $\mathbf{n}$ (\%) & $38(33.9)$ \\
\hline Chronic diseases (such as diabetes mellitus, & $4(3.6)$ \\
\hline hypertension, asthma) & $80(59.3)$ \\
\hline Distant metastasis & $31(23)$ \\
\hline Neurological disorders (dementia, stroke, epilepsy) & $18(13.3)$ \\
\hline Cause of deaths, $\mathbf{n}$ (\%) & $5(3.7)$ \\
\hline Febrile neutropenia & \\
\hline Dependent on disease & \\
\hline Cardiac & \\
\hline Hemorrhage & \\
\hline
\end{tabular}

outcomes between the AAT and survival at the end of the first month and LOS were shown in Table 2. No cut-off value has been yet identified for AAT to reduce the mortality associated with FN guidelines when this study was conducted. Quickly administration of the first dose antibiotics in the ED seems to be reasonable. In our study, each antibiotic cut-off time was as categorized $\leq 1$ vs $>1 \mathrm{~h}, \leq 2$ vs $>2 \mathrm{~h}, \leq 3$ vs $>3 \mathrm{~h}, \leq 4$ vs $>4 \mathrm{~h}$, $\leq 5$ vs $>5 \mathrm{~h}, \leq 6$ vs $>6 \mathrm{~h}$. Analyses were performed for each cutoff value, and no significant relationship was found between AAT and mortality within the first month except $\leq 6$ vs $>6 \mathrm{~h}$. Therefore, timing cut-offs for antibiotics included $\leq 6 \mathrm{~h}$ vs $>6 \mathrm{~h}$. In our study, the mortality rate at the end of the first month was significantly lower $(21.8 \%$ vs $36.1 \%$, respectively) $(p<0.05)$ in $\mathrm{FN}$ patients with an AAT of $\leq 6 \mathrm{~h}$ and $>6 \mathrm{~h}$. Then, logistic regression (LR) analysis of mortality-related risk factors was performed to determine the probability of death at the end of the first month. In the LR analysis, the probability of death at the end of the first month was 2.436 times higher in FN patients with an AAT of $>6$ h compared to other group $(\boldsymbol{p}<0.05)$ (Table 3$)$.

\section{Discussion}

A prolonged AAT can result in adverse outcomes in immunecompromised patients. In our study, the median value of AAT was $247 \mathrm{~min}$, and the mortality rate at the end of the first month was $24.5 \%$. In similar studies, the median AAT ranged from 19.8 to 300 minutes. In the same cohort studies, mortality rates were found to be $2.8 \%$ to $9.4 \%$ at the end of the first month $(1,13$ 17). Our hospital is a tertiary center, and patients, especially with end-stage cancer and comorbid conditions, apply to our ED. There was no particular multidisciplinary approach to quickly identify and treat FN patients in the ED. All of these reasons may have resulted in increased mortality and delayed AAT. Quickly administration of the first dose antibiotics in the ED seems to be reasonable.

In our study, the mortality rate at the end of the first month in FN patients who had first AAT within 6 hours was significantly lower $(21.8 \%$ vs $36.1 \%$, respectively) $(p<0.05)$. In the LR analysis, the probability of death at the end of the first month in patients with an AAT of $>6 \mathrm{~h}$ was found to be 2.436 times higher than the other group $(p<0.05)$. In a recent study, two groups were categorized based on the median AAT. The mortality rate within 28 days in the group with longer AAT was found to be 1.18 times higher than the other group. Also, the delay in the administration of antibiotics every hour increases the mortality rate of $18 \%$ within 28 days (13). Ko et al. (14) categorized the AAT one to four hours, but no significant relationship was found between AAT and mortality within the first 28 days. As a result of our analysis of risk factors associated with mortality at the end 
Table 2. Primary outcomes

\begin{tabular}{|c|c|c|c|c|c|c|c|c|}
\hline \multirow[b]{2}{*}{$\begin{array}{l}\text { Cut-offs for AAT } \\
\text { (hours) }\end{array}$} & \multicolumn{2}{|c|}{$\begin{array}{l}\text { Survival at the end of the first } \\
\text { month } \\
\text { To Hemorrhage }\end{array}$} & \multicolumn{2}{|c|}{$\begin{array}{l}\text { LOS in hospital } \\
\text { (days) }\end{array}$} & \multirow[b]{2}{*}{$\mathrm{U}$} & \multirow[b]{2}{*}{$\mathrm{Z}$} & \multirow[b]{2}{*}{ \#P1 value } & \multirow[b]{2}{*}{$\mu \mathrm{P} 2$ value } \\
\hline & $\begin{array}{l}\text { Alive n (\%) } \\
243(75.5 \%)\end{array}$ & $\begin{array}{l}\text { Dead n (\%) } \\
79(24.5 \%)\end{array}$ & Mean rank & Sum of rank & & & & \\
\hline$\leq 1 \mathrm{~h}$ & $1(100 \%)$ & $0(100 \%)$ & 259.50 & 259.50 & \multirow[b]{2}{*}{61.500} & \multirow[b]{2}{*}{-1.066} & \multirow[b]{2}{*}{$¥ 1$} & \multirow[b]{2}{*}{0.287} \\
\hline$>1 \mathrm{~h}$ & $242(75.4 \%)$ & $79(24.6 \%)$ & 160.69 & 51421.50 & & & & \\
\hline$\leq 2 \mathrm{~h}$ & $10(58.8 \%)$ & $7(41.2 \%)$ & 170.09 & 2891.50 & \multirow[b]{2}{*}{2429.500} & \multirow[b]{2}{*}{-0.416} & \multirow[b]{2}{*}{$¥ 0.143$} & \multirow[b]{2}{*}{0.677} \\
\hline$>2 \mathrm{~h}$ & $233(76.4 \%)$ & $72(23.6 \%)$ & 160.49 & 48789.50 & & & & \\
\hline$\leq 3 \mathrm{~h}$ & $60(69.8 \%)$ & $26(30.2 \%)$ & 164.57 & 14153 & \multirow[b]{2}{*}{9798} & \multirow[b]{2}{*}{-0.418} & \multirow[b]{2}{*}{0.151} & \multirow[b]{2}{*}{0.676} \\
\hline$>3 \mathrm{~h}$ & $183(77.5 \%)$ & $53(22.5 \%)$ & 159.69 & 37528 & & & & \\
\hline$\leq 4 \mathrm{~h}$ & $119(75.8 \%)$ & $38(24.2 \%)$ & 158.98 & 24960 & \multirow{2}{*}{12557} & \multirow{2}{*}{-0.387} & \multirow[b]{2}{*}{0.893} & \multirow[b]{2}{*}{0.702} \\
\hline$>4 \mathrm{~h}$ & $124(75.2 \%)$ & $41(24.8 \%)$ & 162.93 & 26721 & & & & \\
\hline$\leq 5 \mathrm{~h}$ & $167(78 \%)$ & 47 (22\%) & 157.33 & 33512 & \multirow[b]{2}{*}{10721} & \multirow[b]{2}{*}{-0.997} & \multirow[b]{2}{*}{0.131} & \multirow[b]{2}{*}{0.319} \\
\hline$>5 \mathrm{~h}$ & $76(70.4 \%)$ & $32(29.6 \%)$ & 168.23 & 18169 & & & & \\
\hline$\leq 6 \mathrm{~h}$ & $204(78.2 \%)$ & $57(21.8 \%)$ & 161.42 & 41969.50 & \multirow[b]{2}{*}{7820.500} & \multirow[b]{2}{*}{-0.168} & \multirow[b]{2}{*}{0.020} & \multirow[b]{2}{*}{0.866} \\
\hline$>6 \mathrm{~h}$ & 39 (63.9\%) & $22(36.1 \%)$ & 159.20 & 9711.50 & & & & \\
\hline
\end{tabular}

AAT: Antibiotic administration time, LOS: Length of stay \#Chi-square test was used. $\mu$ Mann-Whitney $U$ test was used. ¥Fisher exact test was used.

$\mathrm{p} 1=$ Comparison between AAT and survival at the end of the first month, $\mathrm{p} 2=$ Comparison between AAT and LOS

Table 3. Logistic regression analysis of factors related to mortality at the end of the first month

\begin{tabular}{|c|c|c|c|c|c|}
\hline Variables related to mortality at the end of the first month & B & SE & OR & $(95 \% \mathrm{Cl})$ & p \\
\hline Regression coefficient & -2.791 & 0.380 & 0.061 & & 0.000 \\
\hline$\dagger$ DBP hypotensive patients & 1.03 & 0.344 & 2.726 & $(1.390-5.347)$ & 0.004 \\
\hline †Hypoxic patients & 1.096 & 0.389 & 2.993 & $(1.395-6.421)$ & 0.005 \\
\hline$\dagger C D N$ severe neutropenic patients ${ }^{c}$ & 2.941 & 0.470 & 18.976 & $(7.538-47.565)$ & $<0.001$ \\
\hline$\dagger C D N$ neutropenic patients ${ }^{c}$ & 1.711 & 0.431 & 5.536 & $(2.377-12.897)$ & $<0.001$ \\
\hline$\dagger$ †Positive blood culture & 0.963 & 0.488 & 2.619 & $(1.007-6.815)$ & 0.048 \\
\hline$†$ †atients had no blood culture ${ }^{d}$ & 1.291 & 0.412 & 3.637 & $(1.623-8.150)$ & 0.002 \\
\hline$\dagger$ †Patients with hematological malignancy e & -1.711 & 0.406 & 0.181 & $(0.082-0.401)$ & 0.061 \\
\hline$\dagger \mathrm{AAT}>6 \mathrm{~h}^{\dagger}$ & 0.890 & 0.414 & 2.436 & $(1.081-5.489)$ & 0.032 \\
\hline
\end{tabular}

B: Regression coefficient, SE: Standard error, DBP: diastolic blood pressure, CDN: Count of discharged neutrophil, AAT: Antibiotic administration time, $\dagger$ Reference categories, a: DBP normal and hypertensive, b: Pulse $\mathrm{O}_{2}$ normal, c: CDN normal, d: Negative blood culture, e: Solid tumors, f: AAT $\leq 6 \mathrm{~h}$

of the first month, FN patients who were hypoxic, hypotensive, tachycardic, and tachypnoeic had higher mortality $(p<0.05)$. This situation can be explained by the fact that patients had sepsis or septic shock during admission to the ED. Severe neutropenic or neutropenic patients had higher mortality at the end of the first month compared to the other groups $(p<0.05)$. Patients with hematologic malignancy had 0.181 times higher mortality at the end of the first month $(p<0.05)$. Patients with hematological malignancy receiving chemotherapy are known to have more FN. Perrone et al. (11) found that the admission of patients with underlying hematological malignancies' to an intensive care unit or their mortality risk was 5.5 times higher. Similarly, Rosa and Goldani (13) stated that patients with hematological malignancies had 1.20 times higher mortality than those with solid tumors. 
In our study, the median LOS in the ED was 3 hours. We found that there was no statistically significant relationship. Studies showed that there was no significant relationship between delayed treatment and LOS $(1,14)$.

\section{Study Limitations}

There are several limitations to this study. Due to retrospective design, we might have data losses. Data sources of our study were file records, death notification system, and hospital information system; so, there might be missing data in the records in the system. From 2002 to 2014, with social, economic, and environmental changes, the development of technology and the health care system might have affected the relationship between cause and effect. Further studies are needed with larger patient populations with multiple centers.

\section{Conclusion}

As a result, we found that the administration of the first dose of antibiotics to febrile neutropenic patients in the first six hours is effective in reducing mortality.

\section{Ethics}

Ethics Committee Approval: Retrospective study.

Informed Consent: Retrospective study.

Peer-review: Externally and internally peer-reviewed.

\section{Authorship Contributions}

Surgical and Medical Practices: M.K., S.S., A.A., F.B., Concept: M.K., S.S., A.A., F.B., Design: M.K., S.S., Data Collection or Processing: M.K., S.S., A.A., F.B., Analysis or Interpretation: M.K., S.S., Literature Search: M.K., S.S., A.A., F.B., Writing: M.K., S.S.

Conflict of Interest: No conflict of interest was declared by the authors.

Financial Disclosure: The authors declared that this study received no financial support.

\section{References}

1. Courtney DM, Aldeen AZ, Gorman SM, Handler JA, Trifilio SM, Parada JP, et al. Cancer-Associated Neutropenic Fever: Clinical Outcome and Economic Costs of Emergency Department Care. Oncologist. 2007;12:1019-26.
2. Netterberg I, Karlsson MO, Nielsen El, Quartino AL, Lindman H, Friberg LE. The risk of febrile neutropenia in breast cancer patients following adjuvant chemotherapy is predicted by the time course of interleukin- 6 and C-reactive protein by modelling. Br J Clin Pharmacol. 2018;84:490-500.

3. Freifeld AG, Bow EJ, Sepkowitz KA, Boeckh MJ, Ito JI, Mullen CA, et al. Executive Summary: Clinical Practice Guideline for the Use of Antimicrobial Agents in Neutropenic Patients with Cancer: 2010 Update by the Infectious Diseases Society of America. Clin Infect Dis. 2011;52:427-31.

4. Dang A, Gjolaj LN, Whitman M, Fernandez G. Using Process Improvement Tools to Improve the Care of Patients With Neutropenic Fever in the Emergency Room. J Oncol Pract. 2018;14:e73-81.

5. Lee SJ, Kim JH, Han SB, Paik JH, Durey A. Prognostic Factors Predicting Poor Outcome in Cancer Patients with Febrile Neutropenia in the Emergency Department: Usefulness of qSOFA. J Oncol. 2018;2018:1-7.

6. Nirenberg A, Mulhearn L, Lin S, Larson E. Emergency Department Waiting Times for Patients With Cancer With Febrile Neutropenia: A Pilot Study. Oncol Nurs Forum. 2004;31:711-5.

7. Lin MY, Weinstein RA, Hota B. Delay of Active Antimicrobial Therapy and Mortality among Patients with Bacteremia: Impact of Severe Neutropenia. Antimicrob Agents Chemother. 2008;52:3188-94.

8. Wingard JR, Elmongy M. Strategies for minimizing complications of neutropenia: Prophylactic myeloid growth factors or antibiotics. Crit Rev Oncol Hematol. 2009;72:144-54

9. Legrand M, Max A, Peigne V, Mariotte E, Canet E, Debrumetz A, et al. Survival in neutropenic patients with severe sepsis or septic shock*. Crit Care Med. 2012;40:43-9.

10. Flowers CR, Seidenfeld J, Bow EJ, Karten C, Gleason C, Hawley DK, et al Antimicrobial Prophylaxis and Outpatient Management of Fever and Neutropenia in Adults Treated for Malignancy: American Society of Clinical Oncology Clinical Practice Guideline. J Clin Oncol. 2013;31:794-810.

11. Perrone J, Hollander JE, Datner EM. Emergency Department evaluation of patients with fever and chemotherapy-induced neutropenia. J Emerg Med. 2004;27:115-9.

12. Nasr ZG, Abu Yousef S, Jibril F, Wilby KJ. Critical appraisal of clinical practice guidelines for adult cancer patients with febrile neutropenia. Int J Pharm Pract. 2018;26:49-54.

13. Rosa RG, Goldani LZ. Cohort Study of the Impact of Time to Antibiotic Administration on Mortality in Patients with Febrile Neutropenia. Antimicrob Agents Chemother. 2014;58:3799-803.

14. Ko BS, Ahn S, Lee Y-S, Kim WY, Lim KS, Lee J-L. Impact of time to antibiotics on outcomes of chemotherapy-induced febrile neutropenia. Support Care Cancer. 2015;23:2799-804.

15. Perron T, Emara M, Ahmed S. Time to antibiotics and outcomes in cancer patients with febrile neutropenia. BMC Health Serv Res. 2014;14:162.

16. Szwajcer D, Czaykowski P, Turner D. Assessment and management of febrile neutropenia in emergency departments within a regional health authority-a benchmark analysis. Curr Oncol. 2011;18:280-4.

17. Kim YA, Park YS. Epidemiology and treatment of antimicrobialresistant gram-negative bacteria in Korea. Korean J Intern Med. 2018;33:247-55. 